\title{
BASSO, R. M. Descrição do português brasileiro. São Paulo: Parábola, 2019, 168 pp.
}

\author{
Marcelo Módolo ${ }^{1,2}$ \\ Guilherme Aragão Cardoso 3
}

Este livro da coleção Linguística para o ensino superior baseia-se no funcionamento do português falado no Brasil como língua que possui características estruturais próprias e identidade particular. O objetivo principal do volume é descrever e evidenciar fenômenos característicos do português brasileiro (doravante PB) e marcas identitárias dessa língua capazes de diferenciá-la estrutural, histórica e socialmente do português europeu (doravante $\mathrm{PE}$ ). $\mathrm{O}$ autor parte do instrumental da linguística descritiva para traçar essas diferenças e, embora não conclua taxativamente, sugere que a diferença entre o $\mathrm{PB}$ e o $\mathrm{PE}$ pode não ser absoluta, mas que suas estruturas seguem se distanciando.

A obra pode ser dividida em três grandes unidades de análise. A primeira, introdutória, é destinada à história da língua na América Portuguesa e seus desdobramentos sociopolíticos. A segunda parte apresenta uma breve análise do $\mathrm{PB}$ em todos os seus níveis descritivos

1. Universidade de São Paulo. São Paulo - Brasil. https://orcid.org/0000-0001-5808-9368. E-mail: modolo@usp.br.

2. Bolsista de produtividade em pesquisa do $\mathrm{CNPq}$ - nível 2 (processo número 308793/2019-6).

3. Universidade de São Paulo. São Paulo - Brasil. http://orcid.org/0000-0001-6397-0280.

E-mail: guiaragao@usp.br. 
(fonologia, morfologia, sintaxe, semântica e pragmática), para evidenciar as características específicas do funcionamento do PB falado. Finalmente, a terceira parte traz a complexa tarefa de definir o que é uma língua, tendo em vista os diferentes olhares teóricos sobre o tema e a tentativa de responder à questão principal: “O PB é diferente do PE?".

Comparações entre a fala e a escrita integram, incessantemente, a obra como evidências necessárias para a sustentação do discurso do autor e para a continuidade do livro. As limitações existentes no trabalho, decorrência de políticas editoriais e resultado de fenômenos linguísticos ainda não bem compreendidos, não diminuem o alcance pretendido. $\mathrm{O}$ autor agrupa descrições com enfoques teóricos variados para que a compreensão dos fatos linguísticos seja investigada minuciosamente, evidenciando, contudo, seu próprio posicionamento teórico. A linguagem acessível e dinâmica possibilita ao leitor-alvo, estudantes de Letras e Linguística, uma leitura fluida ausente de hermetismos.

$\mathrm{Na}$ parte introdutória, Basso traça um breve histórico do processo de ocupação colonialista do território até a criação do Atlas linguístico do Brasil em 2014. A historiografia é usada para marcar as principais mudanças ocorridas na colônia e como essas transformações podem ter afetado o desenvolvimento linguístico do PB. Exemplos são a alteração do eixo econômico do nordeste para o sudeste em função da descoberta do ouro no século XVIII e como esse deslocamento, aliado às políticas pombalinas, gerou na colônia a "primeira divisão dialetal no português brasileiro, litoral versus interior" (p. 27). A trajetória da implementação do português dividiu espaço e combinou-se com outras tantas línguas indígenas que foram importantes na formação do PB. Este contato gerou inúmeros topônimos e "cerca de $40 \%$ dos nomes não científicos para peixes e mais de $30 \%$ dos de pássaros têm origem em línguas indígenas" (p. 29). A presença das línguas africanas no acervo lexical é vasta, e sua participação teve um contato mais privado devido à presença do negro no interior da casa-grande e na ocupação urbana após a Abolição da Escravatura. Esse convívio mais próximo com o português falado possibilitou, portanto, a integração de palavras africanas como "caçula", "bunda", "cafuné", entre outras, no léxico do PB. Com o passar dos séculos, o português colonial foi se distanciando paulatinamente do PE e refletindo "a moral, os costumes e o caráter de um povo” (p. 31). Essas características histórico-demográficas 
estruturaram as variedades regionais do português falado no Brasil, tais como o "português caipira", o "sotaque carioca", o "nordestino", o "português urbano" e, também o português "formal" e o "informal". As variações regionais são entendidas como elementos integrantes da diversidade cultural nacional, porque revelam "falantes do português brasileiro que percebem uma realidade linguística diferente" (p. 32). Essas distinções também são interpretadas como marcadores sociais de diferença, por indicarem outras variantes que não a "escolhida" e, por isso, menos prestigiadas. $\mathrm{O}$ autor discorre, no encerramento desta primeira parte, sobre a necessidade de pesquisas mais detalhadas sobre as línguas indígenas e africanas que contribuíram com a formação do $\mathrm{PB}$ e de descrição mais minuciosa das variedades encontradas no Brasil.

$\mathrm{Na}$ segunda parte, o autor analisa as diferenças do funcionamento do PB falado nos níveis fonológico, morfológico, sintático, semântico e pragmático. Na fonologia, o autor apresenta os fonemas do PB, dialogando com Seabra et al. (2015), ao afirmar que os fonemas do PB são divididos em 19 consoantes, sete vogais orais e cinco vogais nasais, totalizando 31 fonemas. Segundo o autor, uma das diferenças fonêmicas encontradas entre o PB e o PE é a conservação dos fonemas /ə/ e / / / na variante europeia. O primeiro, conhecido como "schwa", é uma vogal em posição neutra que, segundo o autor, causa-nos a impressão de que os portugueses "comem as letras" por se tratar de um som diferente para nós e, por isso, de difícil percepção auditiva. O último faz a distinção entre $<$ mal $>$ e $<$ mau $>$, sendo a primeira realizada com a ponta da língua encostada na região palatal em oposição à segunda, uma vogal fechada e posterior. No Brasil, em regiões específicas, é possível encontrar a rara pronúncia do / / /, falada principalmente por pessoas idosas. Outro ponto de análise é o funcionamento da escrita frente à pronúncia do $\mathrm{PB}$ e os fenômenos encontrados quando contrastamos fala e ortografia. $\mathrm{O}$ autor aborda as palavras "escola", "estojo", "então" e "espelho", que começam com o $<\mathrm{e}>$ pretônico e são realizadas como [i]. Embora a convenção ortográfica nos obrigue a escrever essas palavras com $<\mathrm{e}>$, nós as ouvimos e as pronunciamos como iscola, istojo, intão e ispelho. Outro caso semelhante é o dos ditongos escritos com $<$ ei $>$ e $<$ ou $>$ e o fenômeno da monotongação. Na fala, as semivogais /i/ e /u/ praticamente desaparecem, dando lugar a "sequências sonoras" (p. 52), como acontece nas palavras "queijo" [quezu] e "touro" [toru]. Entretanto, o apagamento das semivogais não alterou o modo como escrevemos 
e mantemos $\mathrm{o}<\mathrm{i}>$, mesmo quando a realidade da fala se aproxima de quejo, bejo e mantega. Vale ressaltar que o autor não deixa claro se a monotongação é um fenômeno exclusivo do $\mathrm{PB}$, como na situação do $<$ e $>$ pretônico. Para Basso, esses fenômenos criam um terreno de investigação que nos ajuda a entender possíveis reformas futuras da língua e a desenvolver melhores estratégias para resolver problemas de alfabetização.

Na morfologia, o autor se pauta pela seguinte afirmativa: "a lição importante aqui é que nenhuma categoria linguística é um dado natural, inabalável, mas sim construtos teóricos sempre passíveis de revisão e reformulação" (p. 69). É o caso de definir "palavra", que, segundo o autor, não se define por si só e, por isso, é preciso empregá-la dentro de um contexto maior de análise, pois "podemos pensar em critérios fonológicos, sintáticos, morfológicos e semânticos e veremos que eles não chegam aos mesmos resultados" (p. 65). É como se a palavra precisasse passar por diferentes ritos de batismo antes de receber um "nome" único.

No léxico, a perspectiva sociolinguística adotada pelo autor reflete alguns casos razoavelmente bem estudados no $\mathrm{PB}$, tais como os de concordância verbal e nominal, em casos com mais de uma regra para marcar o plural nominal, em que ora marcamos obrigatoriamente o artigo ou um demonstrativo, ora "marcamos opcionalmente os elementos depois do artigo" (p. 73). Outros casos abordados são o uso de "tudo" como possível marcador de plural, como "os menino tudo chegaram", o uso do "a gente" conjugando verbos na primeira pessoa do plural, tal como "a gente fomos", a aférese do verbo "estar" que resulta na fala "tamo em algum lugar", o uso do presente do indicativo expresso de forma perifrástica, envolvendo um verbo auxiliar e um verbo principal, resultando em "não posso sair agora porque estou tomando banho" em vez de "não posso sair agora porque tomo banho". Para Basso (p. 75), isso "significa que todo sistema verbal está se rearranjando!". O mais importante é que "a informação linguística é a mesma, gostemos disso ou não, e é esse fato que importa à descrição de língua, pois estamos diante de duas regras que expressam uma mesma informação" (p. 74).

Sobre a sintaxe, o autor aponta dois casos peculiares do PB que fogem à regra convencional. Basicamente, o português segue a lógica 
do SVO (sujeito, verbo e objeto). Entretanto, o PB usa organizações sintáticas diferentes de SVO, e o autor chama essa organização de construção de tópico, que opera da seguinte forma: "apagamos o sujeito (agente) e mudamos para seu lugar o objeto" (p. 105). A interpretação é a do resultado da ação e não sobre quem praticou a ação. É o caso da frase "o leite esfriou" em vez de "o leite está frio". Além desse caso, a situação do objeto nulo no PB também ganhou destaque. No PE não é comum objeto nulo. O preenchimento do objeto no $\mathrm{PE}$ aparece frequentemente com um pronome átono, como em "João comprou um livro e leu-o ontem". No PB, por sua vez, "preferimos não dizer nada, que é a estratégia do objeto nulo" (p. 102), ou se usam os pronomes do caso reto ou, até mesmo, repetem-se partes da frase dita anteriormente. Em outras palavras, no PB temos a possibilidade de dizer "João comprou um livro e leu ele ontem" ou "João comprou um livro e leu o livro ontem". Ainda sobre os pronomes átonos, os clíticos, Basso destaca a ocorrência habitual de estruturas com próclise nas quais o pronome átono é o primeiro elemento da sentença e há o uso de pronomes do caso reto no lugar de pronomes átonos. $\mathrm{O}$ autor questiona os motivos pelos quais a variação do uso da próclise no PB é reputada como erro, uma vez que essa variação está presente nas manifestações da fala do brasileiro. Basso cita o poema "Pronominais", de 1925, de autoria de Oswald de Andrade, para historicizar essa ocorrência e pergunta: "O que há de objetivamente errado nessa variação?”.

No campo da semântica e da pragmática, o autor apresenta três situações de casos próximos à maneira como falamos no Brasil. A primeira é o caso do(s) "nome(s) nu(s)", termo que designa "substantivos, no singular ou no plural, que não são precedidos por nenhum artigo ou demonstrativo" (p. 126-27). Ou seja, no português há substantivos que são contáveis e outros que são não contáveis (massivos). Os contáveis ganham forma no singular e no plural, porque são objetos individualizados no mundo; assim, temos "gato" e "gatos". "Água", por sua vez, não é contável, porque nomeia uma porção não recortada ou não individualizada da realidade. Portanto, a rigor, "água" não tem plural. No caso do PB, os substantivos contáveis ganham forma no singular nu e no plural nu sem distinguir a quantidade exata. Por exemplo, quando dizemos "tem maçã na geladeira" não nos referimos à quantia exata de fruta na geladeira. A informação importante é a de que há fruta ali e, sobretudo, o falante, em determinado contexto, saberá compreender a 
mensagem, mesmo que na fala não haja marcação do plural ou especificidade numérica. A forma singular nu "carrega" a pluralidade e a singularidade ao mesmo tempo no sistema gramatical brasileiro. Para Basso, "o nosso uso do singular nu é uma verdadeira marca registrada do PB" (p. 128).

A segunda situação é o uso do verbo "poder" como marcador de imperativo. $\mathrm{O}$ verbo pode introduzir os sentidos de permissão, possibilidade e capacidade, que conferem quase o sentido oposto do imperativo. Basso compreende que a falta de aprofundamento sobre o tema impossibilita uma resposta conclusiva. Por isso, o autor sugere que "um item modal pode ter diversas interpretações, que compartilham um núcleo comum de ser uma possibilidade ou uma necessidade" (p. 131).

A manipulação da verdade é algo marcante atualmente, quando se fala em poder. Aumentar ou diminuir uma informação ou colocá-la em dúvida é algo que o $\mathrm{PB}$ desenvolveu como elemento próprio. Basso traz, assim, a terceira situação semântico-pragmática do PB: o uso dos artigos indefinidos "uns" e "umas" para tornar uma informação menos precisa. São os possíveis artigos indefinidos - possíveis, pois o autor sugere uma forma semelhante ao artigo indefinido, porém com outra função, na qual assume o descompromisso com a verdade da informação. Similarmente, o "meio" também opera como redutor da precisão e da verdade. O verbo "achar" recebe a atenção do autor por se tratar de um termo que pode exigir evidência direta ou indireta e denotar falta de certeza. No caso de evidência direta, o autor compreende que o uso de "achar" só pode ser irônico, uma vez que o verbo desqualifica a própria certeza do falante.

Nos capítulos finais, o foco se concentra na política linguística e destaca relações de poder relevantes para a manutenção, implementação, divulgação, planejamento e até extinção de línguas. A história do Brasil revela como essas relações se desdobraram em diferentes instâncias sociais e como efetivamente impactaram a forma como lidamos hoje com o PB e com outras línguas faladas em território nacional. Brevemente, o autor rememora episódios que marcaram a língua enquanto instrumento político, tais como: O Diretório dos Índios de 1757, a Semana de Arte Moderna de 1922, o Congresso da Língua Cantada de 1936, o Congresso Brasileiro de Língua Falada no 
Teatro de 1957, o Decreto-Lei redigido por Getúlio Vargas em 1938, a oficialização das línguas indígenas Nheengatu, Tukano e Baniwa no estado do Amazonas em 2002, a oficialização e legalização da LIBRAS em 2002, e a criação da Comunidade do países de língua portuguesa (CPLP) em 1996. Esta última colocação suscita a discussão sobre as diferenças e a inteligibilidade como parâmetros de distanciamento entre o PB e o PE.

A compreensibilidade entre as línguas é um critério que valida a imagem de uma mesma língua. O problema desse critério é que a inteligibilidade deslegitima a variedade informal, pois considera as diferenças históricas, lexicais, regionais, geracionais e sociais como elementos insuficientes para separá-las em línguas distintas. É como se o argumento se fundamentasse na ideia de que a parte não altera o todo. No caso da variação formal, é possível que haja um grau maior de identificação, pois o Brasil mantém o ensino da língua portuguesa veiculado a uma gramática imobilizada na cultura letrada portuguesa. Por isso, a variante formal aproxima ambas as variantes. Segundo o autor, entretanto, "as variedades formais têm características que as tornam um tanto irreais, pois elas são variedades mais congeladas" (p. 156). A variante formal não representa a realidade da fala e, por conseguinte, a existência de mundos linguísticos diferentes. A consequência dessa disparidade é a legitimidade de uma única variante (unidade idealizada) como a correta, aceitável, polida e culta. Em outras palavras, a perspectiva que iguala as línguas ignora as diferenças encontradas nas variantes formais e informais, tornando-as irrelevantes. Dessa maneira, Basso nos apresenta uma possível inconsistência no critério da inteligibilidade e da unidade idealizada como argumentos para a construção política da imagem de uma mesma língua.

Para tentar sanar essa inconsistência, o autor mobiliza o princípio de determinação de língua. Sugere, então, definir línguas por meio de suas características estruturais. Ou seja, as línguas serão iguais se compartilharem dos mesmos elementos (fonológico, morfológico e sintático) e das mesmas regras gramaticais para o seu padrão de funcionamento. Esse critério, entretanto, é problemático porque "não sabemos direito como utilizá-lo" (p. 157). Basso questiona se a única diferença entre uma língua e outra está unicamente na forma de fazer as perguntas: "Seriam elas então diferentes?" "Iguais?" "Uma vez que apresentam 
mais semelhanças do que diferenças, seriam 'parecidas'?”. Não há uma resposta simples. Diferentes ou iguais, o ponto de vista teórico e metodológico de quem pesquisa os temas linguísticos ou de quem faz a pergunta é relevante. $\mathrm{O}$ autor afirma que há diferentes perspectivas para um mesmo problema e que elas são guiadas por teorias discutidas pelos especialistas há anos. Assim como uma "régua", a perspectiva teórica se torna o meio pelo qual as distâncias e as diferenças entre as línguas são medidas e, portanto, capazes de produzirem diferentes respostas para uma mesma pergunta.

Diante do exposto acima, é possível que consigamos entender que não existe uma única e simples resposta sobre a identidade entre o PB e o PE. Podemos compreender que o PB e o PE são diferentes por causa das dessemelhanças estruturais que cada um apresenta. Também podemos aceitar a perspectiva de que ambos são iguais e, portanto, as diferenças representam ganhos significativos à unidade da língua portuguesa. Seja qual for a "régua", o livro permite discutir a história, as diferenças sociolinguísticas, as relações de poder, o domínio cultural por meio da língua e a falta de pesquisas mais detalhadas sobre a estrutura do PB. Tentar definir algo não é tarefa fácil, ainda mais se tratando de um fenômeno em constante mudança e de uma extensa teorização epistemológica. Dessa forma, podemos pensar nas sugestões e provocações do autor como incentivo para adentrar o universo da linguística. A linguagem clara, dinâmica e objetiva da obra é um convite aos estudantes de Letras, Linguística e aos entusiastas do assunto a questionar os padrões de funcionamento da língua portuguesa no Brasil para melhor entendê-la.

\section{Referências}

SEABRA, I. C. et al. 2015. Para conhecer: fonética e fonologia do português brasileiro. São Paulo: Contexto.

Recebido em: 28/07/2020

Aprovado em: 05/10/2020 